Jerzy Siwek

\title{
SHOULD MAPS BE NICE-LOOKING?
}

The rapidly developing computer technologies exert a strong influence on cartography, an influence which cannot be readily interpreted. On the one hand, modern technologies increase the possibilities regarding the recording, processing and presenting of spatial information: a new type of maps has become quite common - they can be seen only on computer screens and differ both in preparation and perception from traditional maps. In addition, computerisation does undoubtedly have a positive influence on the technical aspects of traditional maps, which are nowadays sometimes referred to as "paper maps", by allowing for an extremely precise print and rendering of the cartographic image. On the other hand, however, technical perfection is not always matched by the semiotic correctness of maps. This is due to the fact that those who introduce modern technologies to map-making normally do not pay sufficient attention to the correctness of methodology and the graphic layout of maps, focusing mainly on those computer software possibilities which are associated with data processing, treating the visualisation of the processed results (cartographic presentation) as a "by-product". Thus, paradoxically, the introduction of "novelties" frequently produces ugly maps. Nonetheless, it might be asked whether, in the times of chasing for copious and speedy information, the graphic form of maps has any significance whatsoever. That is, should maps be nice-looking?

The shortest answer to this question is as follows: "Maps should be nicelooking, even to the point of beautiful". It seems that this statement can be justified both on aesthetic grounds and in terms of the effectiveness of the communicated content.

The aesthetic value of maps results from the fact that they are graphic products, subject to the rules governing such type of representations. Until recently, this statement would not give rise to any doubts. However, in the era of advanced numerical technologies its legitimacy is not obvious to everybody. Opinions can be encountered that "one can work with the map without the map", that is, the traditional, "paper" map, having a graphic form. Recently, maps have also come to denote, especially in the circles of "numerical cartographers", the record of spatial information in a barely numerical form. The map is equated with the numerical data base. Maps thus understood are 
reduced to mere information, and information itself, indeed, does not have to look nice in any way.

It should be borne in mind that the map-data base saved in the computer memory is stratified, with any required number of strata corresponding to individual issues. They can occur separately or in sets which in case of visualisation, on the computer screen or as a hard copy, does not guarantee either good readability or methodological correctness. No such hazard (if the ignorance of the maker is excluded) exists in the case of the "usual" map, which is always compiled focusing on a pre-defined set of issues, limited by the graphical capacity of a given "sheet of paper".

The evaluation of maps in aesthetic categories (ugly - nice-looking) is tantamount to the evaluation of its form. Unlike works of fine arts, such as paintings for example, the map cannot be regarded as "pure form" since it always carries some contents. Therefore, a nice-looking map is not only an adequate graphical composition, but also a harmony of contents and form which carries information. It is not of no importance to map users what information can be read from the map and how fast, or whether this information is complete or distorted, for example by graphical noise occurring as a result of wrong application of colours, shapes etc.

This brings us to the heart of the problem, that is the efficiency of the communication of information. Simplifying it a little, it can be said that efficient communication can only be ensured by a nice-looking map (the nicer the map the more efficient the communication), a map with an elegant form which, in a deliberate and justified manner, reflects the content. This means that the system of cartographic signs making up the map must be logically structured, that is, compiled according to sensible assumptions, and the signs themselves must be readable individually and collectively, that is, when they add up to make the map, occurring in different spatial patterns. Thus, the three known semiotic relationships should be present: semantic, syntactic and pragmatic.

The logic of the sign system, best visible in the map key, is manifested in two spheres: substantive and cartographic. A manifestation of substantive logic is a suitable layout of content, that is, arranging the issues e.g. according to their importance, chronology or causative order. The adopted content layout should be matched by the cartographic logic. This means selecting such methods of cartographic presentation which would best render the nature of the presented phenomena (e.g. atmospheric pressure is shown with isobars, that is, using the isoline method, and not in measurement points on a diagram map, even though the latter method would be easier). It also involves a suitable construction of cartographic signs. Whenever possible, it should result from the associations with the presented objects and phenomena.

The logic of contents translated into the language of graphics leads to visual order. Thus, the content arranged in terms of substance should also be graphically arranged. This should be understood as giving a related graphic form to objects and facilities with similar characteristics. As an 
example, one can quote the structure of signatures representing natural resources according to the principles formulated by L. Ratajski - the minerals belonging to the same group have the common leading shape (Ratajski, 1971). Secondly, such sign graphics are desirable which would render the hierarchy of content - that is, those signs which represent the issues intended as the key ones should be best visible and should constitute the primary plane of reading, while the remaining ones should have a lower optical weight, corresponding to the lower rank of the content. The visual order on the map, reflecting the harmony of form and substance, can be achieved by means of a skilful application of graphic variables.

Our considerations so far have aimed to show how significant role in the communication of cartographic information is played by the map's graphical aspect. Naturally, it is rather difficult to question the view that map is information, but it should be stressed that there is more to the map than information itself. Not questioning the fundamental significance of the informative function of the map, the form of the message should not be ignored or underestimated. Therefore, it is not only the content, but also the form of the message since it affects the quality of the reception of the communicated information. Those who have different views and who do not attach particular attention to the graphic aspect of maps may use maps which are ugly yet rich in content. One wonders how much they can read and remember (and with what effort!) from a map on which the signs do not arrange the content in order but merely differentiate it, from a map that is graphically "flat", without the reading levels, or from a map which departs from the traditional use of colours, on which - for instance - the waters are red, the forests green, and the built-up areas - blue.

Ignoring the role of graphics in map applications testifies to the ignorance of the gist of cartographic communication, in which a significant part is played by hidden information which, according to L. Ratajski, is hidden in the "interplay" of cartographic signs on the map (Ratajski, 1977). The ability to interpret this "interplay" leads to the revealing of the information, which should be regarded as a gain of information as compared to the one which is contained in the signs themselves. It seems obvious that thus acquired information depends on the logical and semiotic correctness of the map which has been mentioned above which, in turn, is associated with its aesthetic values, that is, beauty.

Rejecting the aesthetic value of maps would undermine the efforts going many centuries back and aimed at perfecting their graphical side, efforts which frequently produced astonishing results. Suffice it to list the Swiss and German topographical maps and school atlases, Polish pre-war topographical maps or many sheets of the International Map of the World 1:1 M. A particularly good example of "beautifying" the map is shading of the land relief, which is probably this graphic activity among those used in cartography that is closest to art. There is little exaggeration in saying that its precursors were the painters of the Italian Baroque who were masters of 
light-and-shade effects (maniera tenebrosa). Shading put on a contour map practically does not add any new information to the already existing one. It is a redundancy, and therefore a definitely superfluous element for "numerical" cartographers. And yet, generations of cartographers put their efforts in making it more perfect just for the sake of its aesthetic values, for its beauty.

There is one more pertinent argument for nice-looking maps, a didactic one. If we want to improve the cartographic culture of the society we must start with the youngest. And which child, of their own and free will, will take any interest in an ugly map? Maps for children should be particularly attractive graphically, because the graphic aspect in this respect is more important than the content. And, we should part with the illusion that nice-looking maps can be made for children, while the aesthetic aspect will not matter for the remaining users because it is only information that does matter. Ugly maps for adults will produce ugly maps for children, which is going to make the cartographic "illiteracy" even worse. This is another thing that should be realised by all those who do not appreciate or even depreciate the meaning of beauty in cartography.

\section{REFERENCES}

R a t aj s ki L., 1971, Logiczno-semiotyczne zasady uporządkowania i standaryzacji znaków kartograficznych [Logical-semiotic principles of arrangement and standardization of cartographic signs], Part II, Polski Przeglqd Kartograficzny, 3, No. 4, 156-166.

Ratajski L., 1977, Straty i zyski informacji w przekazie kartograficznym [Losses and gains of information in cartographic communication], Polski Przeglqd Kartograficzny, 9, 97-104. 